Journal of Mathematics and Statistics 1 (2): 160-164, 2005

ISSN 1549-3644

(C) Science Publications, 2005

\title{
Busy Period Analysis of a Man-machine System Operating Subject To Different Physical Conditions
}

\author{
${ }^{1}$ G.S. Mokaddis, ${ }^{1}$ M.L. Tawfek and ${ }^{2}$ S.A.M. Elhssia \\ ${ }^{1}$ Department of Mathematics, Faculty of Science, Ain Shams University, Cairo, Egypt \\ ${ }^{2}$ Department of Mathematics, Faculty of Science, Omar El-Mokhtar University, Beida, Libya
}

\begin{abstract}
This study deals with some characteristics of a single-unit of a man-machine system operating under different physical conditions. The failure, repair and change of physical conditions (good-poor) are stochastically independent random variables each having an arbitrary distribution. The system analysed by some Markov process technique. The busy period, expected number of visits by the repairman and the cost per unit time in a steady state of the system are obtained. Several important results have been derived as particular cases.
\end{abstract}

Keywords: Busy Period, Failure, Repair, Regenerative State, Availability.

\section{INTRODUCTION}

Several authors have studied the single-unit system under different conditions ${ }^{[1,2]}$. This study deals with the busy period analysis of a single-unit oif man-machine system operating subject to different physical conditions. The failure, repair and physical conditions (good-poor) are stochastically independent random variables each having an arbitrary distribution. Using the semi Markov process technique and the results of the regenerative process. The distribution time to the system failure, the mean time to system failure, pointwise availability and steady state availability are obtained Mokaddis et al. ${ }^{[3]}$. The purpose of the present study is to study the busy period analysis by the server and the expected number of visits by the server. The results obtained by Dhillon ${ }^{[1]}$ are derived from this study as special cases. The following assumptions and notations are used to analyse the system:

- The system consists of a single unit which can operate by a person in good or poor physical conditions.

- The unit fails in one of three ways, the first is due to hardware failure, the second is due to human error when operator is in good physical condition and the third is due to human error when operator is in poor physical condition.

- Failure, physical conditions and repair times are stochastically independent random variables each having an arbitrary distribution.

- The operator reports to work in good physical condition which may change to poor and vice versa physical condition are stochastically independent random variables each having an arbitrary distribution.

- When the system is down and the operator is in good physical condition, it cannot deteriorate as he is supposed to be at rest.

- There is a single repair facility with the system to repair the failed unit.

- On repair of the failed unit, it acts like a new unit.

- All random variables are mutually independent.

\section{NOTATIONS AND STATES OF THE SYSTEM}

$\mathrm{E}_{0} \quad$ State of the system at epoch $\mathrm{t}=0$,

E Set of regenerative states; $\left\{S_{0}, S_{1}, S_{2}\right.$,

$\left.-\quad \mathrm{S}_{3}, \mathrm{~S}_{4}, \mathrm{~S}_{5}\right\}$,

$E \quad$ Set of non-regenerative state;

$\left\{S_{6}, S_{7}\right\}$.

$\mathrm{f}(\mathrm{t}), \mathrm{F}(\mathrm{t}) \quad$ pdf and cdf of failure time of the unit due to hardware failure,

$f_{1}(t), F_{1}(t) \quad$ pdf and cdf of failure time of the unit due to human error; where, the operator is in good physical condition,

$\mathrm{f}_{2}(\mathrm{t}), \mathrm{F}_{2}(\mathrm{t}) \quad$ pdf and cdf of failure time of the unit due to human error; where, the operator is in poor physical condition,

$\lambda(t) \quad$ pdf and cdf of change of physical condition from good mode to poor mode,

$h(t), H(t) \quad$ pdf and cdf of change of physical condition from poor mode to good mode,

$\mathrm{g}(\mathrm{t}), \mathrm{G}(\mathrm{t}) \quad$ pdf and cdf of time to repair the unit from hardware failure, 
$\mathrm{g}_{1}(\mathrm{t}), \mathrm{G}_{1}(\mathrm{t}) \quad$ pdf and cdf of time to repair the unit from human error; where the operator is in good physical condition,

$\mathrm{g}_{2}(\mathrm{t}), \mathrm{G}_{2}(\mathrm{t}) \quad$ pdf and cdf of time to repair the unit due to human error; where the operator is in poor physical condition,

$\mathrm{q}_{\mathrm{ij}}(\mathrm{t}), \mathrm{Q}_{\mathrm{ij}}(\mathrm{t}) \quad$ pdf and cdf of first passage time from regenerative state $i$ to a regenerative state $\mathrm{j}$ or to a failed state $\mathrm{j}$ without visiting any other regenerative state in $(0, \mathrm{t}] ; \mathrm{i}, \mathrm{j} \in \mathrm{E}$,

$\mathrm{q}_{\mathrm{ij}}^{(\mathrm{k})}(\mathrm{t}), \mathrm{Q}_{\mathrm{ij}}^{(\mathrm{k})}(\mathrm{t}) \quad$ pdf and cdf of first passage time from regenerative state $i$ to a regenerative state $\mathrm{j}$ or to a failed state $\mathrm{j}$ without visiting any other regenerative state in $(0, \mathrm{t}] ; \mathrm{i}, \mathrm{j} \in \mathrm{E}, \overline{\mathrm{E}}$,

$\mathrm{p}_{\mathrm{ij}} \quad$ One step transition probability from $\mathrm{p}_{\mathrm{ij}}^{(\mathrm{k})}$ $\pi_{\mathrm{i}}(\mathrm{t})$

$\mathrm{A}_{\mathrm{i}}(\mathrm{t})$

$M_{i}(t)$

$\mathrm{B}_{\mathrm{i}}(\mathrm{t})$

$\mathrm{V}_{\mathrm{i}}(\mathrm{t})$

$\mu_{\mathrm{ij}}$

$\mu_{\mathrm{i}}$

$\sim \quad$ Symbol for
transform, e.g. $\tilde{F}(s)=\int e^{-s t} d F(t)$,

Symbol for Laplace transform, e.g. $\mathrm{f}^{*}(\mathrm{~s})=\int \mathrm{e}^{-\mathrm{st}} \mathrm{f}(\mathrm{t}) \mathrm{dt}$,

S
(C)

Symbol for ordinary convolution, e.g. $a(t)(b)=\int_{0}^{t} a(u) b(t-u) d u$.

For simplicity, whenever integration limits are $(0, \infty)$, they are not written.

\section{Symbols used for the state}

o Operative unit,

d The physical condition is good,

$\mathrm{p}$ The physical condition is poor,

$\mathrm{r}$ The failed unit is under repair when failed due to hardware failure,

$r_{1}$ The failed unit is under repair when failed due to human error; where the operator is in good physical condition,

$r_{2}$ The failed unit is under repair when failed due to human error; where the operator is in poor physical condition,

$\mathrm{R}$ The unit is in continued repair; where the failure is due to hardware failure,

$\mathrm{R}_{2}$ The unit is in continued repair when failed due to human error; where the operator is in poor physical condition.

Considering these symbols, the system may be in one of the following states at any instant where the first letter denotes the mode of unit and the second corresponds to physical condition

$$
\begin{aligned}
& \mathrm{S}_{0} \equiv(\mathrm{o}, \mathrm{d}), \quad \mathrm{S}_{1} \equiv(\mathrm{o}, \mathrm{p}), \quad \mathrm{S}_{2} \equiv(\mathrm{r}, \mathrm{d}), \quad \mathrm{S}_{3} \equiv\left(\mathrm{r}_{1}, \mathrm{~d}\right), \\
& \mathrm{S}_{4} \equiv(\mathrm{r}, \mathrm{p}), \quad \mathrm{S}_{5} \equiv\left(\mathrm{r}_{2}, \mathrm{p}\right), \quad \mathrm{S}_{6} \equiv(\mathrm{R}, \mathrm{d}), \quad \mathrm{S}_{7} \equiv\left(\mathrm{R}_{2}, \mathrm{~d}\right) \text {. }
\end{aligned}
$$

Stated and possible transitions between them are shown in Fig. 1.

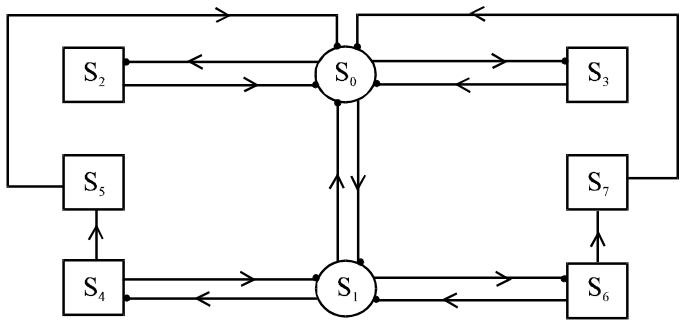

○ Up state $\square$ Down state - Regeneration point

Fig. 1

\section{BUSY PERIOD ANALYSIS}

Elementary probability arguments yield the following relations for $\mathrm{B}_{\mathrm{i}}(\mathrm{t})$

$$
\begin{aligned}
& \mathrm{B}_{0}(\mathrm{t})=\mathrm{q}_{01}(\mathrm{t}) \subseteq \mathrm{B}_{1}(\mathrm{t})+\mathrm{q}_{02}(\mathrm{t}) \subset \mathrm{B}_{2}(\mathrm{t})+\mathrm{q}_{03}(\mathrm{t}) \subseteq \mathrm{B}_{3}(\mathrm{t}), \\
& \mathrm{B}_{1}(\mathrm{t})=\mathrm{q}_{10}(\mathrm{t}) \subseteq \mathrm{B}_{0}(\mathrm{t})+\mathrm{q}_{14}(\mathrm{t}) \subseteq \mathrm{B}_{4}(\mathrm{t})+\mathrm{q}_{15}(\mathrm{t}) \subseteq \mathrm{B}_{5}(\mathrm{t}),
\end{aligned}
$$


$\mathrm{B}_{2}(\mathrm{t})=\mathrm{V}_{2}(\mathrm{t})+\mathrm{q}_{20}(\mathrm{t}) \odot \mathrm{B}_{0}(\mathrm{t})$

$\mathrm{B}_{3}(\mathrm{t})=\mathrm{V}_{3}(\mathrm{t})+\mathrm{q}_{30}(\mathrm{t}) \subset \mathrm{B}_{0}(\mathrm{t})$,

$\mathrm{B}_{4}(\mathrm{t})=\mathrm{V}_{4}(\mathrm{t})+\mathrm{q}_{41}(\mathrm{t}) \odot \mathrm{B}_{1}(\mathrm{t})+\mathrm{q}_{40}^{(6)}(\mathrm{t}) \odot \mathrm{B}_{0}(\mathrm{t})$,

$\mathrm{B}_{5}(\mathrm{t})=\mathrm{V}_{5}(\mathrm{t})+\mathrm{q}_{51}(\mathrm{t}) \odot \mathrm{B}_{1}(\mathrm{t})+\mathrm{q}_{50}^{(7)}(\mathrm{t}) \odot \mathrm{B}_{0}(\mathrm{t})$

Where:

$$
\begin{array}{lll}
\mathrm{V}_{2}(\mathrm{t})=\overline{\mathrm{G}}(\mathrm{t}) \overline{\mathrm{L}}(\mathrm{t}) \quad, & \mathrm{V}_{3}(\mathrm{t})=\overline{\mathrm{G}}_{1}(\mathrm{t}) \overline{\mathrm{L}}(\mathrm{t}), \\
\mathrm{V}_{4}(\mathrm{t})=\overline{\mathrm{G}}(\mathrm{t}) \overline{\mathrm{H}}(\mathrm{t}) \quad, & \mathrm{V}_{5}(\mathrm{t})=\overline{\mathrm{G}}_{2}(\mathrm{t}) \overline{\mathrm{H}}(\mathrm{t})
\end{array}
$$

Taking Laplace transforms of Eq. 1 and solving for $\mathrm{B}_{0}^{*}(\mathrm{~s})$, it gives:

$$
\mathrm{B}_{0}^{*}(\mathrm{~s})=\mathrm{N}_{2}(\mathrm{~s}) / \mathrm{D}_{1}(\mathrm{~s})
$$

Where:

$$
\begin{aligned}
\mathrm{N}_{2}(\mathrm{~s})= & \left(\mathrm{q}_{02}^{*} \mathrm{~V}_{2}^{*}+\mathrm{q}_{03}^{*} \mathrm{~V}_{3}^{*}\right)\left(1-\mathrm{q}_{14}^{*} \mathrm{q}_{41}^{*}-\mathrm{q}_{15}^{*} \mathrm{q}_{51}^{*}\right) \\
& +\mathrm{q}_{01}^{*}\left(\mathrm{q}_{14}^{*} \mathrm{~V}_{4}^{*}+\mathrm{q}_{15}^{*} \mathrm{~V}_{5}^{*}\right)
\end{aligned}
$$

and

$$
\begin{aligned}
\mathrm{D}_{1}= & \left(1-\mathrm{p}_{01}\right)\left(\mu_{14} \mathrm{p}_{41}+\mathrm{p}_{14} \mu_{41}+\mathrm{p}_{15} \mu_{51}+\mu_{15} \mathrm{p}_{51}\right) \\
& +\left(1-\mathrm{p}_{14} \mathrm{p}_{41}-\mathrm{p}_{15} \mathrm{p}_{51}\right)\left(\mu_{02}+\mathrm{p}_{02} \mu_{20}+\mathrm{p}_{03} \mu_{30}+\mu_{03}\right) \\
& +\mu_{01}\left(\mathrm{p}_{10}+\mathrm{p}_{14} \mathrm{p}_{40}^{(6)}+\mathrm{p}_{15} \mathrm{p}_{50}^{(7)}\right) \\
& +\mathrm{p}_{01}\left(\mu_{10}+\mu_{14} \mathrm{p}_{40}^{(6)}+\mathrm{p}_{14} \mu_{40}^{(6)}+\mathrm{p}_{15} \mu_{50}^{(7)}\right. \\
& \left.+\mu_{15} \mathrm{p}_{50}^{(7)}\right)
\end{aligned}
$$

In long run the fraction of time for which the server is busy is given by:

$$
\mathrm{B}_{0}(\infty)=\mathrm{N}_{2} / \mathrm{D}_{1},
$$

Where:

$$
\begin{aligned}
\mathrm{N}_{2}= & \left(\mathrm{p}_{02} \mu_{2}+\mathrm{p}_{03} \mu_{3}\right)\left(1-\mathrm{p}_{14} \mathrm{p}_{41}-\mathrm{p}_{15} \mathrm{p}_{51}\right) \\
& +\mathrm{p}_{01}\left(\mathrm{p}_{14} \mu_{4}+\mathrm{p}_{15} \mu_{5}\right)
\end{aligned}
$$

and

$D_{1}$ is given by (4).

The expected busy period of server facility in $(0, t]$ is: $\mu_{b}(t)=$ expected busy time of the repairman in $(0, t]$.
The repairman may be busy during $(0, t]$ starting from initial state $\mathrm{S}_{0}$.

Hence,

$$
\mu_{\mathrm{b}}(\mathrm{t})=\int_{0}^{\mathrm{t}} \mathrm{B}_{0}(\mathrm{u}) \mathrm{du}
$$

so that

$$
\mu_{\mathrm{b}}^{*}(\mathrm{~s})=\mathrm{B}_{0}^{*}(\mathrm{~s}) / \mathrm{s}
$$

Thus one can evaluate $\mu_{\mathrm{b}}(\mathrm{t})$ by taking inverse Laplace transform of $\mu_{\mathrm{b}}^{*}(\mathrm{~s})$.

Expected idle time of the repairman in $(0, t]$ is

$$
\mu_{1}(\mathrm{t})=1-\mu_{\mathrm{b}}(\mathrm{t}) \text {. }
$$

\section{EXPECTED NUMBER OF VISITS BY THE REPAIRMAN}

Elementary probability arguments yield the following relations for $B_{i}(t)$

$$
\begin{aligned}
\mathrm{V}_{0}(\mathrm{t})= & \mathrm{Q}_{01}(\mathrm{t}) \mathrm{s}\left[1+\mathrm{V}_{1}(\mathrm{t})\right]+\mathrm{Q}_{02}(\mathrm{t}) \mathrm{s}\left[1+\mathrm{V}_{2}(\mathrm{t})\right] \\
& +\mathrm{Q}_{03}(\mathrm{t}) \mathrm{s}\left[1+\mathrm{V}_{3}(\mathrm{t})\right] \\
\mathrm{V}_{1}(\mathrm{t})= & \mathrm{Q}_{10}(\mathrm{t}) \mathrm{s}\left[1+\mathrm{V}_{0}(\mathrm{t})\right]+\mathrm{Q}_{14}(\mathrm{t}) \mathrm{s}\left[1+\mathrm{V}_{4}(\mathrm{t})\right] \\
& +\mathrm{Q}_{15}(\mathrm{t}) \mathrm{s}\left[1+\mathrm{V}_{5}(\mathrm{t})\right] \\
\mathrm{V}_{2}(\mathrm{t})= & \mathrm{Q}_{20}(\mathrm{t}) \mathrm{s}_{0}(\mathrm{t}) \\
\mathrm{V}_{3}(\mathrm{t})= & \mathrm{Q}_{30}(\mathrm{t}) \mathrm{V}_{0}(\mathrm{t}) \\
\mathrm{V}_{4}(\mathrm{t})= & \mathrm{Q}_{41}(\mathrm{t}) \mathrm{s}_{1}(\mathrm{t})+\mathrm{Q}_{40}^{(6)}(\mathrm{t}) \mathrm{sV}_{0}(\mathrm{t}) \\
\mathrm{V}_{5}(\mathrm{t})= & \mathrm{Q}_{51}(\mathrm{t}) \mathrm{s}_{1}(\mathrm{t})+\mathrm{Q}_{50}^{(7)}(\mathrm{t}) \mathrm{sV}_{0}(\mathrm{t})
\end{aligned}
$$

Taking Laplace-Stieltjes transforms of Eq. (1) and solving for $\mathrm{V}_{0}^{*}(\mathrm{~s})$, dropping the argument $\mathrm{s}$ for brevity, it follows:

$$
\mathrm{V}_{0}^{*}(\mathrm{~s})=\mathrm{N}_{3}(\mathrm{~s}) / \mathrm{D}_{2}(\mathrm{~s}),
$$

Where:

$$
\begin{aligned}
\mathrm{N}_{3}(\mathrm{~s})= & \left(1-\tilde{\mathrm{Q}}_{01}+\tilde{\mathrm{Q}}_{02}+\tilde{\mathrm{Q}}_{03}\right)\left(1-\tilde{\mathrm{Q}}_{14} \tilde{\mathrm{Q}}_{41}-\tilde{\mathrm{Q}}_{15} \tilde{\mathrm{Q}}_{51}\right) \\
& +\tilde{\mathrm{Q}}_{01}\left(\tilde{\mathrm{Q}}_{10}+\tilde{\mathrm{Q}}_{14}+\tilde{\mathrm{Q}}_{15}\right)
\end{aligned}
$$

and

$$
\begin{aligned}
\mathrm{D}_{2}(\mathrm{~s})= & \left(1-\tilde{\mathrm{Q}}_{02} \tilde{\mathrm{Q}}_{20}-\tilde{\mathrm{Q}}_{03} \tilde{\mathrm{Q}}_{30}\right)\left(1-\tilde{\mathrm{Q}}_{14} \tilde{\mathrm{Q}}_{41}-\tilde{\mathrm{Q}}_{15} \tilde{\mathrm{Q}}_{51}\right) \\
& -\tilde{\mathrm{Q}}_{01}\left(\tilde{\mathrm{Q}}_{10}+\tilde{\mathrm{Q}}_{14} \tilde{\mathrm{Q}}_{40}^{(6)}+\tilde{\mathrm{Q}}_{15} \tilde{\mathrm{Q}}_{50}^{(7)}\right)
\end{aligned}
$$


In steady state, number of visits per unit is given by:

$$
\mathrm{V}_{0}(\infty)=\mathrm{N}_{3} / \mathrm{D}_{2}
$$

Where:

$\mathrm{N}_{3}=1+\mathrm{p}_{01}-\mathrm{p}_{14} \mathrm{p}_{41}-\mathrm{p}_{15} \mathrm{p}_{51}$

$\mathrm{D}_{2}=\mathrm{p}_{01}\left[1-\mathrm{p}_{10}-\mathrm{p}_{14}\left(\mathrm{p}_{41}+\mathrm{p}_{40}^{(6)}\right)-\mathrm{p}_{15}\left(\mathrm{p}_{51}+\mathrm{p}_{50}^{(7)}\right)\right](5)$

\section{COST ANALYSIS}

The cost function of the system obtained by considering the mean-up time of the system, expected busy period of the server and the expected number of visits by the server, therefore, the expected profit incurred in $(0, \mathrm{t}]$ is:

$$
\begin{aligned}
\mathrm{C}(\mathrm{t}) & =\text { expected total revenue in }(0, \mathrm{t}] \\
& \text { - expected total service cost in }(0, \mathrm{t}] \\
& \text { - expected cost of visits by server in }(0, \mathrm{t}] \\
& =\mathrm{K}_{1} \mu_{\mathrm{up}}(\mathrm{t})-\mathrm{K}_{2} \mu_{\mathrm{b}}(\mathrm{t})-\mathrm{K}_{3} \mathrm{~V}_{0}(\mathrm{t})
\end{aligned}
$$

The expected profit per unit time in steady-state is:

$$
\mathrm{C}=\mathrm{K}_{1} \mathrm{~A}_{0}-\mathrm{K}_{2} \mathrm{~B}_{0}-\mathrm{K}_{3} \mathrm{~V}_{0}
$$

Where, $K_{1}$ is the revenue per unit up time, $K_{2}$ is the cost per unit time for which system is under repair and $\mathrm{K}_{3}$ is the cost per visit by repair facility.

\section{SPECIAL CASES}

The single unit with failure and repair exponentially distributed:

Let

$\alpha$ Failure rate of the unit due to hardware failure,

$\beta \quad$ Failure rate of the unit due to human error; where the operator is in good physical condition,

$\gamma \quad$ Failure rate of the unit due to human error; where the operator is in poor physical condition,

$\delta$ Change of physical condition rate from good mode to poor mode,

$\theta$ Change of physical condition rate from poor mode to good mode,

$\omega$ Repair rate of the unit from hardware failure,

$\lambda$ Repair rate of the unit from human error; where the operator is in good physical condition,

$\varepsilon \quad$ Repair rate of the unit from human error; where the operator is in poor physical condition.

\begin{tabular}{|c|c|c|c|}
\hline \multirow[b]{2}{*}{$\beta$} & \multicolumn{3}{|l|}{$\mathrm{C}$} \\
\hline & $\delta=0.4$ & $\delta=0.6$ & $\delta=0.8$ \\
\hline 0.1 & 998.1833 & 1226.7330 & 1401.331 \\
\hline 0.2 & 785.9746 & 1014.0950 & 1183.079 \\
\hline 0.3 & 612.1279 & 842.9411 & 1008.1970 \\
\hline 0.4 & 464.8877 & 700.7023 & 863.8236 \\
\hline 0.5 & 336.9454 & 579.4864 & 741.7718 \\
\hline 0.6 & 223.4917 & 474.0720 & 636.5713 \\
\hline 0.7 & 121.2211 & 380.8579 & 544.4236 \\
\hline 0.8 & 27.7779 & 297.2745 & 462.6036 \\
\hline 0.9 & 10.5644 & 221.4357 & 389.1040 \\
\hline
\end{tabular}

Transition probabilities are:

$$
\mathrm{p}_{01}=\delta /(\delta+\alpha+\beta) \quad, \quad \mathrm{p}_{02}=\alpha /(\delta+\alpha+\beta),
$$

Table 1:

\begin{tabular}{lrrr}
\hline & C & & \\
& -1 & & \\
$\alpha$ & $\delta=0.3$ & $\delta=0.5$ & $\delta=0.8$ \\
\hline 0.1 & 1024.2690 & 1298.3750 & 1564.9260 \\
0.2 & 826.5411 & 1075.1180 & 1322.3090 \\
0.3 & 639.8087 & 890.6446 & 1123.4460 \\
0.4 & 476.2774 & 734.9694 & 957.9896 \\
0.5 & 330.6919 & 601.2720 & 818.3685 \\
0.6 & 199.2988 & 484.7160 & 698.9977 \\
0.7 & 100.3174 & 381.7681 & 595.7105 \\
0.8 & 51.9091 & 189.7883 & 505.3575 \\
0.9 & 23.8333 & 206.7642 & 425.5283 \\
\hline
\end{tabular}

Table 2:

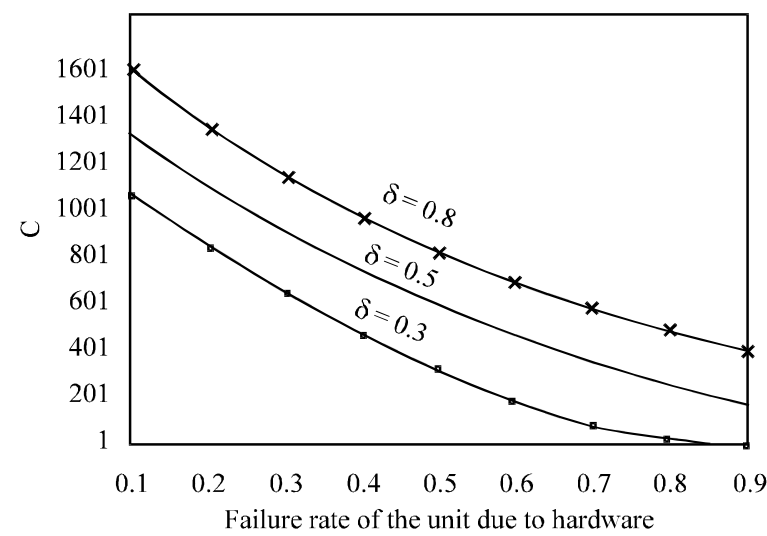

Fig. 2: Relation between the failure rate of the unit due to hardware failure and the cost per unit time

$$
\begin{array}{rlrl}
\mathrm{p}_{03} & =\beta /(\delta+\alpha+\beta), & \mathrm{p}_{10}=\theta /(\theta+\alpha+\gamma), \\
\mathrm{p}_{14}=\alpha /(\theta+\alpha+\gamma), & \mathrm{p}_{15}=\gamma /(\theta+\alpha+\gamma), \\
\mathrm{p}_{41}=\omega /(\omega+\theta), & \mathrm{p}_{46}=\theta /(\omega+\theta), \\
\mathrm{p}_{51}=\varepsilon /(\varepsilon+\theta), & \mathrm{p}_{57}=\theta /(\varepsilon+\theta), \\
\mathrm{p}_{40}^{(6)}=\theta \omega /(\theta+\omega)(\omega+\delta), & \\
\mathrm{p}_{50}^{(7)}=\theta \varepsilon \omega /(\theta+\varepsilon)(\varepsilon+\delta) .
\end{array}
$$

The mean sojourn times are:

$$
\begin{array}{lll}
\mu_{0}=1 /(\alpha+\beta+\delta) & , & \mu_{1}=1 /(\alpha+\gamma+\theta), \\
\mu_{2}=1 /(\omega+\delta) & , & \mu_{3}=1 /(\lambda+\delta), \\
\mu_{4}=1 /(\omega+\theta) & , & \mu_{5}=1 /(\varepsilon+\theta) .
\end{array}
$$


Table 3:

\begin{tabular}{llcc}
\hline & C & & \\
$\gamma$ & $-10-0$ & & \\
$\gamma$ & $\theta=0.2$ & $\theta=0.4$ & $\theta=0.6$ \\
\hline 0.1 & 1884.574 & 1657.749 & 1479.912 \\
0.2 & 1808.792 & 1628.560 & 1474.749 \\
0.3 & 1754.425 & 1603.204 & 1466.649 \\
0.4 & 1717.041 & 1582.434 & 1458.143 \\
0.5 & 1693.305 & 1566.145 & 1450.294 \\
0.6 & 1680.808 & 1553.974 & 1443.551 \\
0.7 & 1677.841 & 1545.511 & 1438.081 \\
0.8 & 1673.205 & 1540.367 & 1433.920 \\
0.9 & 1669.083 & 1538.083 & 1431.036 \\
\hline
\end{tabular}

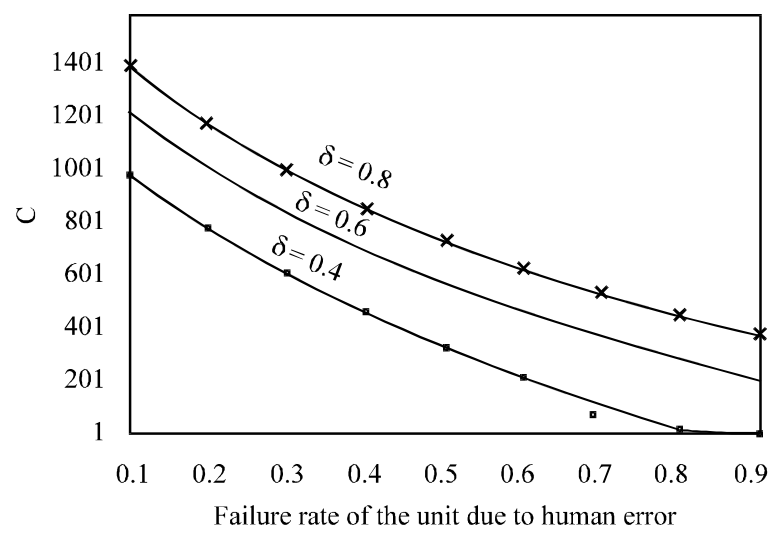

Fig. 3: Relation between the failure rate of the unit due to human error; where the operator is in good physical condition and the cost per unit time

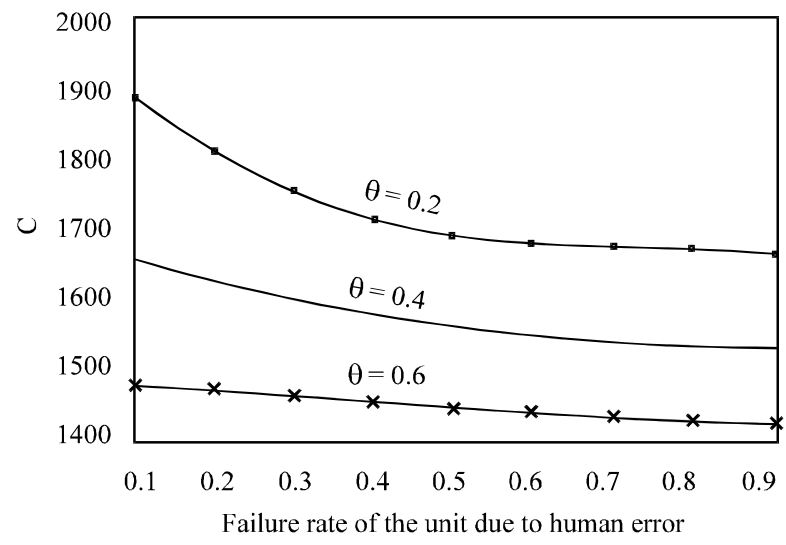

Fig. 4: Relation between the failure rate of the unit due to human error; where the operator is in poor physical condition and the cost per unit time

In this case, $\hat{\mathrm{V}}_{\mathrm{i}}(\mathrm{t})$ are:

$$
\begin{array}{ll}
\hat{\mathrm{V}}_{2}(\mathrm{t})=\mathrm{e}^{(\omega+\delta) \mathrm{t}}, & \hat{\mathrm{V}}_{3}(\mathrm{t})=\mathrm{e}^{-(\lambda+\delta) \mathrm{t}} \\
\hat{\mathrm{V}}_{4}(\mathrm{t})=\mathrm{e}^{(\omega+\theta) \mathrm{t}}, & \hat{\mathrm{V}}_{2}(\mathrm{t})=\mathrm{e}^{-(\varepsilon+\theta) \mathrm{t}}
\end{array}
$$

In long run, the function of time for which the server is busy is given by:

$$
\hat{\mathrm{B}}_{0}(\infty)=\hat{\mathrm{N}}_{2} / \hat{\mathrm{D}}_{1},
$$

Where:

$$
\begin{aligned}
\hat{\mathrm{N}}_{2}=\frac{1}{(\delta+\alpha+\beta)}\left[\begin{array}{c}
\frac{1}{(\omega+\delta)}+ \\
\frac{1}{(\lambda+\delta)}
\end{array}\right]\left\{\begin{array}{l}
1-\frac{1}{(\theta+\alpha+\gamma)} \times \\
{\left[\frac{\alpha \omega}{(\omega+\theta)}+\frac{\gamma \varepsilon}{(\varepsilon+\theta)}\right]}
\end{array}\right\} \\
+\frac{\delta}{(\delta+\alpha+\beta)(\theta+\alpha+\gamma)}\left[\frac{\alpha}{(\omega+\theta)}+\frac{\gamma}{(\varepsilon+\theta)}\right]
\end{aligned}
$$

In steady state, number of visits per unit is given by

Where:

$$
\hat{\mathrm{V}}_{0}(\infty)=\hat{\mathrm{N}}_{3} / \hat{\mathrm{D}}_{2}
$$

$$
\begin{gathered}
\hat{\mathrm{N}}_{3}=1+\frac{\delta}{(\delta+\alpha+\beta)}-\frac{1}{(\theta+\alpha+\gamma)}\left[\frac{\alpha \omega}{(\omega+\theta)}+\frac{\gamma \varepsilon}{(\varepsilon+\theta)}\right], \\
\hat{D}_{2}=\frac{\delta}{(\delta+\alpha+\beta)}\left\{1-\frac{\theta}{(\theta+\alpha+\gamma)}-\frac{\alpha \omega}{(\theta+\alpha+\gamma)(\omega+\theta)}\left[1+\frac{\theta}{(\omega+\theta)}\right]-\right. \\
\quad-\frac{\lambda \varepsilon}{(\theta+\alpha+\gamma)(\varepsilon+\theta)}\left[1+\frac{\theta}{(\varepsilon+\delta)}\right] .
\end{gathered}
$$

The expected profit per unit time in steady state is

$$
\hat{\mathrm{C}}=\mathrm{K}_{1} \hat{\mathrm{A}}_{0}-\mathrm{K}_{2} \hat{\mathrm{B}}_{0}-\mathrm{K}_{3} \hat{\mathrm{V}}_{0} .
$$

\section{Numerical example:}

Let

$\mathrm{K}_{1}=2000, \mathrm{~K}_{2}=100, \mathrm{~K}_{3}=50, \beta=0.3, \gamma=0.7, \theta=0.5$, $\omega=0.6, \lambda=0.4, \varepsilon=0.1$

Let,

$\mathrm{K}_{1}=2000, \mathrm{~K}_{2}=100, \mathrm{~K}_{3}=50, \alpha=0.5, \gamma=0.4, \theta=0.5, \omega$ $=0.6, \lambda=0.5, \varepsilon=0.1$

Let,

$\mathrm{K}_{1}=5000, \mathrm{~K}_{2}=150, \mathrm{~K}_{3}=20, \alpha=0.3, \beta=0.1, \delta=0.7$, $\omega=0.1, \lambda=0.1, \varepsilon=0.1$

\section{REFERENCES}

1. Dhillon, B.S., 1980. On human reliability bibliography. Microelectron. Reliab., 20: 371.

2. Goel, L.R., A. Kumar and A.K. Rastogi, 1985. Stochastic behaviour of man-machine systems operating under different weather conditions. Microelectron. Reliab., 25: 87-91.

3. Mokaddis,G.S.,M.L. Tawfek and S.A.M.El-Hssia, 1997 Some Characteristics a Man-machine System Operating Subject to Different Weather Conditions,Microelectron.reliab., Vol.37,No.3,493496. 